Article

\title{
Effect of Addition of Pectins from Jujubes (Ziziphus jujuba Mill.) on Vitamin C Production During Heterolactic Fermentation
}

\author{
Alessia Fazio ${ }^{1, *}$, Chiara La Torre ${ }^{1}$, Maria Cristina Caroleo ${ }^{1}$, Paolino Caputo ${ }^{2}{ }^{\mathbb{D}}$, \\ Roberto Cannataro $^{1}\left(\mathbb{D}\right.$, Pierluigi Plastina ${ }^{1}\left(\mathbb{D}\right.$ and Erika Cione ${ }^{1}(\mathbb{D})$ \\ 1 Department of Pharmacy, Health and Nutritional Sciences, Department of Excellence 2018-2022, \\ University of Calabria, Edificio Polifunzionale, 87036 Rende (CS), Italy; latorre.chiara@libero.it (C.L.T.); \\ mariacristinacaroleo@virgilio.it (M.C.C.); r.cannataro@gmail.com (R.C.); pierluigi.plastina@unical.it (P.P.); \\ erika.cione@unical.it (E.C.) \\ 2 Department of Chemistry and Chemical Technologies, University of Calabria, 87036 Rende (CS), Italy; \\ paolino.caputo@unical.it \\ * Correspondence: a.fazio@unical.it; Tel.: +39-0984-493013
}

Academic Editors: Lourdes Arce and Gordon Morris

Received: 25 April 2020; Accepted: 9 June 2020; Published: 11 June 2020

\begin{abstract}
Soluble fibers, including pectins from apple and lemon, are commonly used as prebiotic and to prepare functional foods. The present study aimed to investigate the physicochemical and functional properties of pectins extracted from jujubes (Ziziphus jujuba Mill.). Pectins were extracted from jujubes at three stages of harvesting and characterized by FTIR and SEM analyses. Whole milk inoculated with kefir grains was supplemented by $0.25 \mathrm{mg} \cdot \mathrm{mL}^{-1}$ of pectins. The $\mathrm{pH}$ value and vitamin $C$ content were evaluated after 24 and $48 \mathrm{~h}$ of fermentation. Pectins from jujubes at the first harvesting stage (PJ1K) showed the lowest methoxylation degree. The addition of pectins enhanced the production of vitamin $C$ during heterolactic process. This result was found to depend on jujube harvesting stage as PJ1K stimulated the growth of yeasts in kefir grains yielding to the highest amount of vitamin $C\left(0.83 \pm 0.01 \mu \mathrm{g} \cdot \mathrm{mL}^{-1}\right)$ compared to other samples $\left(0.53-0.60 \mu \mathrm{g} \cdot \mathrm{mL}^{-1}\right)$ at $24 \mathrm{~h}$. Lactic acid bacteria diminish $\mathrm{pH}$ rapidly with respect to control $(4.13 \pm 0.05)$, according to the stage of maturation, reducing its initial value by $38.3 \%$ in PJ1K. Besides being an excellent prebiotic, pectins from jujubes could be used to enrich kefir with vitamin C.
\end{abstract}

Keywords: jujube; harvesting stage; pectin; methoxylation degree; kefir; vitamin C; heterolactic fermentation

\section{Introduction}

Jujube is the fruit of the Ziziphus plant that is widespread in China and other regions of Asia and Australia as well as in the Mediterranean basin. In China, its cultivation area has reached the remarkable amount of more than 1.5 million ha, with an annual fruit production of 400,000 tons and an export of US $\$ 5$ million [1]. Jujube fruits have been reported to have multiple biological functions due to the presence of bioactive compounds including phenolics, triterpenoids, saponins, and non-starch polysaccharides. These bioactive compounds have been used in the prevention and treatment of human diseases, such as inflammatory diseases, cancers, liver damage, and wound healing [2-5]. In particular, its content in dietary fiber contributes to consider it a healthy choice of food [6]. Pectins are polysaccharide derivatives representing the major component of the primary cell walls and middle lamella of plant tissues, where they function as hydrating agents and cementing material for the cellulosic network [7]. In the pharmaceutical field, they find a variety of applications as a tool to reduce blood cholesterol and to prevent various types of cancers [7], while they are used in the food 
industry as gelling agent and stabilizer [8]. Pectins are food components that have beneficial effects on human health as they possess prebiotic nature and nutraceutical properties and act as a delivery vehicle for probiotics, and for these reasons they find positive utilization in promoting health by modulation of intestinal microbiota [9]. It has been reported that the addition of prebiotics, such as inulin [10] or fructooligosaccharides (FOS) [11], to fermented milks influences physicochemical and sensory properties, as well as microbiological growth, vitamins, and organic acid formation. In this context, kefir is a fermented dairy beverage with an alcoholic flavor, easy to digest, and rich in probiotic microbiota [12].

Kefir comes from the Caucasus Mountains, and is produced by incubating milk with kefir grains [13] or freeze-dried concentrated cultures that are even considered to lead to a more uniform and stable product, thus guaranteeing its commercial value $[14,15]$. The most common microorganisms present in kefir are lactic acid bacteria (Lactobacillus, Leuconostoc, Streptococcu, and Lactococcus ssp), fermenting yeasts (Kluyveromyces, Saccharomyces), and acetic bacteria $[15,16]$. Lactic acid bacteria (LAB) can be responsible for both homofermentation that produces lactic acid and heterofermentation leading to acetic acid, ethanol, carbon dioxide, formic acid, and lactic acid [17]. This beverage is a recognized probiotic dairy product [18]: Its beneficial properties are well known and currently there is a positive trend for its consumption [19]. Kefir is an example of probiotic mixture of bacteria and yeasts [20], which take part to complex interactions contributing to the symbiosis equilibrium and can influence product characteristics and quality [21]. In this regard, it is useful to highlight that kefir also lends itself to "natural" vitamin fortification [12]. Interestingly, Di Matteo et al. [22] have reported that the ascorbic acid content is associated with the expression of genes involved in pectin degradation. Although synthetic vitamin $C$ can be readily added to food, there is an increasing awareness and resistance among the consumers to the use of synthetic additives in food materials and a tightening of the legislation on food and drink artificial fortification [23]. These results prompted us to explore the possible influence of pectins on the synthesis of vitamin $C$ by the kefir microorganisms. Although the effect of the addition of apple- and lemon-soluble fibers to kefir on rheological, microbiological, and sensorial properties has been reported [24,25], to the best of our knowledge, there are no data available in the literature about the effect of pectin addition on chemical composition of milk kefir. In order to obtain functional and biofortified foods, the objective of this study was to evaluate the effect of the addition of pectins extracted from Chinese dates (jujubes) (Ziziphus jujuba Mill.) on vitamin C production during kefir heterolactic fermentation in whole milk.

\section{Results and Discussion}

\subsection{Extraction of Pectins}

In order to valorize jujube fruits, chemical and morphological characterization of jujube pectins was assessed and, as a result, the effects of three different stages of jujube harvesting on methoxylation degree of extracted pectins were assessed. The diverse properties of pectins depend on the food matrix from which they are extracted and on the isolation method, all factors that influence the methoxylation degree.

Extraction of pectins from jujube fruits was performed by using citric acid under reflux. The choice of this acid instead of diluted mineral acids, such as sulfuric, hydrochloric, and nitric acids, is due to the advantages it offers as regards the environmental impact and the economic aspect [26]. Pectin recoveries from jujubes of the first, second, and third harvesting were $48 \pm 4 \mathrm{mg} \cdot \mathrm{g}^{-1}$ ( $4.8 \%$ yield), $37 \pm 3 \mathrm{mg} \cdot \mathrm{g}^{-1}$ (3.7\% yield), and $21.9 \pm 0.6 \mathrm{mg} \cdot \mathrm{g}^{-1}(2.2 \%$ yield $)$, respectively. These results showed that the pectin content changed markedly as jujube fruit ripened: Extraction yield was halved at the third ripening stage $(2.2 \%)$ compared to that of the first harvest $(4.8 \%)$.

In line with our results, it has been reported that pectin content from jujubes of different cultivars, extracted by dissimilar methods [27] ranged from 3 to $7.5 \%$. This highlights that the jujube fruit could represent a promising alternative source of pectins, in particular at the first stage of maturation. 


\subsection{FTIR Spectroscopic Analysis}

The FTIR spectra of pectins from jujubes (PJ) of first, second and third harvesting (PJ1, PJ2, PJ3, respectively) are reported in Figure 1. Typical bands appeared in the spectra, as it is expected for pectin molecules, which prove that the extracted substances were pectins; the bands characterizing the structure did not show significant differences, except for their relative absorption intensities, at the three stages of harvesting. The characteristic bands, around $3640-3680 \mathrm{~cm}^{-1}$, are generated by $\mathrm{OH}$ stretching, due to inter- and intramolecular hydrogen bonding of the galacturonic acid backbone. The band at around $2924-2928 \mathrm{~cm}^{-1}$ is due to $\mathrm{CH}$ stretching and bending vibrations of galacturonic ring. Another important region is the fingerprint region $1750-1350 \mathrm{~cm}^{-1}$, where the bands allowed the detection of esterified (methylated) vs. unesterified functional groups. The extracted pectins from jujubes of all harvesting periods revealed in this spectral region two bands at $1748 \mathrm{~cm}^{-1}$ and $1647 \mathrm{~cm}^{-1}$. The first one is due to the $\mathrm{C}=\mathrm{O}$, ester carbonyl groups' stretching, and the second one is generated by $\mathrm{COO}^{-}$carboxylate ion stretching [28]. In the so-called "fingerprint region" (1300 to $\left.900 \mathrm{~cm}^{-1}\right)$ [29], the band at $1425 \mathrm{~cm}^{-1}$ is originated from the symmetric and asymmetric stretching vibration of the methyl group in ester, while bending vibration of $\mathrm{OH}$ group in pyranose ring generated the band at $1235-1230 \mathrm{~cm}^{-1}$. The bands occurring at $900-910,1008-1004$, and $1040 \mathrm{~cm}^{-1}$ were generated from $\mathrm{C}-\mathrm{C}$ stretching, $\mathrm{C}-\mathrm{O}-\mathrm{H}$ deformation, and asymmetric $\mathrm{C}-\mathrm{O}-\mathrm{C}$ stretching vibration. In addition, the weak band at $840 \mathrm{~cm}^{-1}$ indicated the ring vibration of $\alpha$-glycosidic linkage. These bands were characteristic for pectins [30].

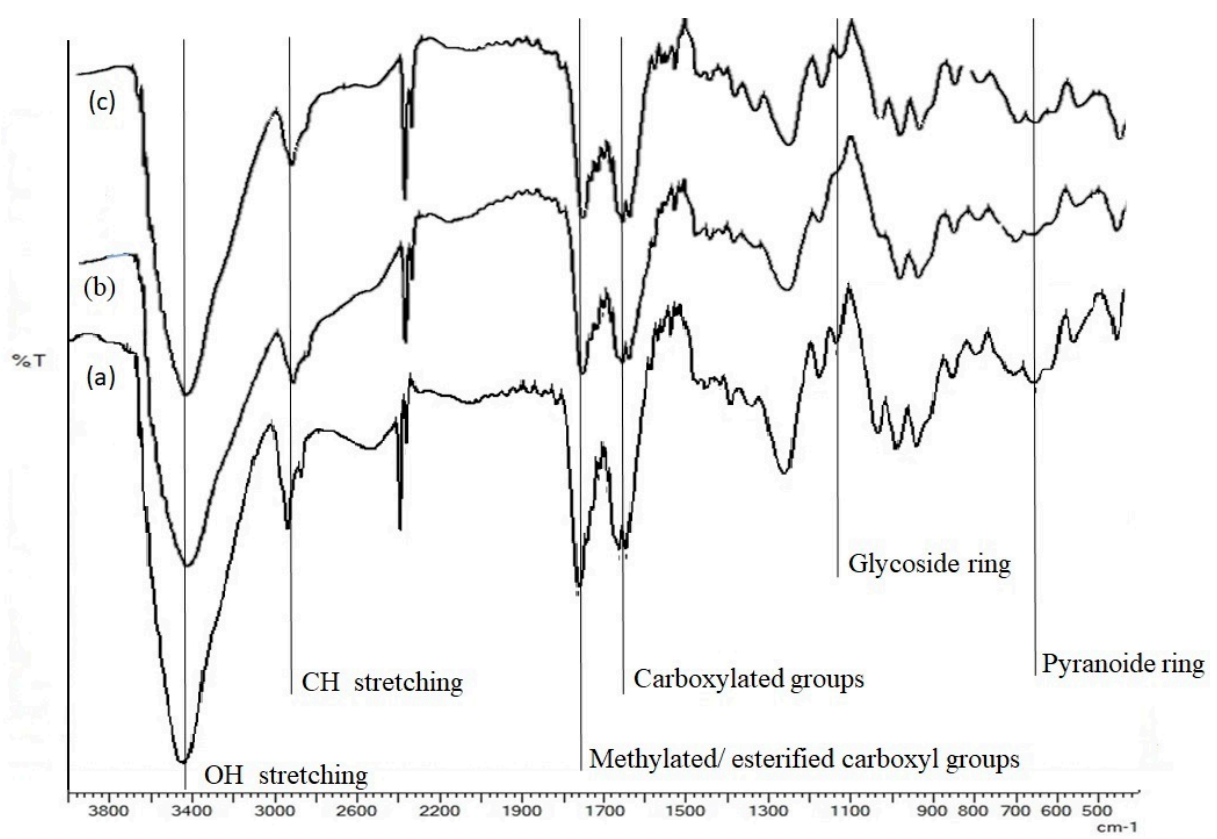

Figure 1. FTIR spectra of pectins in the 400 to $4000 \mathrm{~cm}^{-1}$ region. Spectra of pectins from jujubes (PJ) of first harvesting, PJ1 (a), second harvesting, PJ2 (b) and third harvesting, PJ3 (c).

\subsection{Scanning Electron Microscopy}

The structural characterization of pectin samples was performed by scanning electron microscopy (SEM) equipped with wavelength dispersive spectroscopy (WDS). SEM images (Figure 2A-I) with different magnifications, providing visual surface morphology features of dried pectin particles, showed that different degrees of fruit ripeness could affect the microstructures of pectins. It can be seen that the surface of PJ1 was compact (Panel A) with the presence of micro-cracks and elongated holes of the order of hundreds of microns. In the panels B and C with greater magnification (2500x and 5000x, respectively) irregular lamellar structure with different thicknesses, which was closely packed, is visible. Panel D shows that pectins from J2 have rough texture and plenty of surface irregularities. At higher 
magnifications (panels E-F), it is possible to see a very porous structure with intercommunicating cavities of dimensions up to the order of tens of microns. Panel G shows a dense, amorphous structure which was soft and could curl easily, devoid of porosity and cavity. At high magnifications, it can be seen that the surface of PJ3 was dense and stratified (panel H) with shallow pitting (panel I). Then, it is possible to state that the three samples have a different degree of porosity and compactness, ranging from the extremely porous (panels D, E, F) to the more compact and non-porous (panels G, H, I), passing through an intermediate situation (panels $\mathrm{A}, \mathrm{B}, \mathrm{C}$ ).

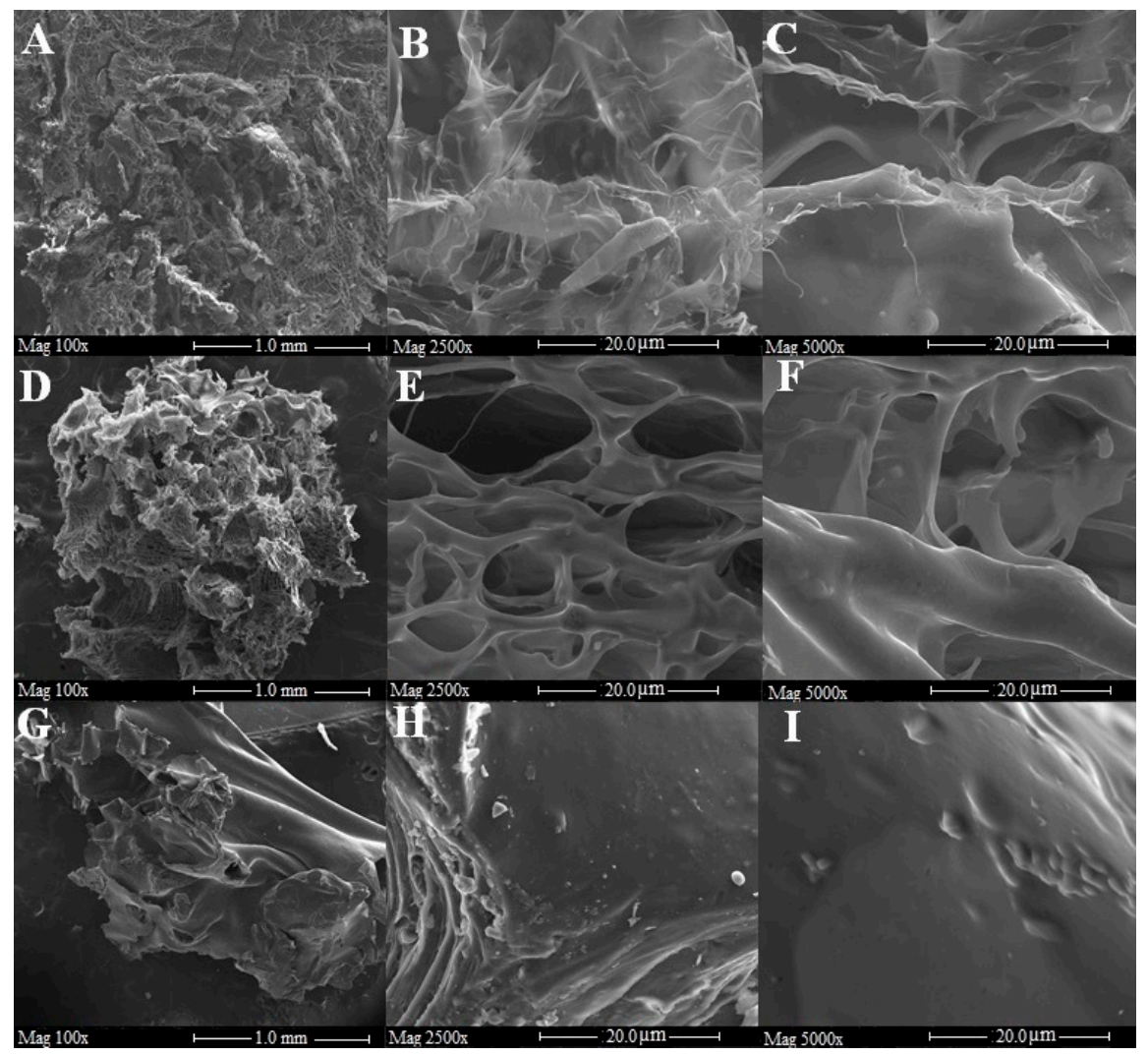

Figure 2. Scanning electron images of PJ1 (A-C), PJ2 (D-F), and PJ3 (G-I). The magnification of (A,D,G) is equal to $100 \times$ with a scale of $1 \mathrm{~mm}$; magnification of $(\mathbf{B}, \mathbf{E}, \mathbf{H})$ is equal to $5000 \times$ with a scale of $20 \mu \mathrm{m}$; magnification of $(\mathbf{C}, \mathbf{F}, \mathbf{I})$ is equal to $2500 \times$ with a scale of $20 \mu \mathrm{m}$.

The Wavelength Dispersive X-ray Spectroscopy (WDS) analysis was performed in order to determine the variation of the chemical composition in the pectin matrix during the maturation period under study.

Table 1 presents the results of the WDS measurements in the pectin samples. The data were an average of three measurements in various particles of each sample. WDS analysis results revealed that the main element in all samples is the carbon followed by the oxygen, while nitrogen is a negligible percentage, whose content ranged from $1.24 \%$ in PJ1 to $1.92 \%$ in PJ3. The carbon percentage increased from 46.17 (PJ1) to 69.87 (PJ3), while the oxygen percentage increased at the second stage of harvesting $(12.93 \%)$ and remained constant at the third stage. The findings demonstrated that the ripening process had effect on the morphological characteristics of jujube pectins [31]. Probably, during the harvesting period under study, as the maturation proceeded, the color of the jujubes underwent the increase in redness and the loss of greenness, as shown in Figure 1, without affecting the texture of fruit, which retained its hardness. These aspects confirmed that softening process, caused by the degradation and solubilization of cell wall polysaccharides, had not yet begun at the third harvesting period; the depolymerization of the homogalacturonan backbone by higher polygalacturonase [32] was not yet started, as confirmed by the increase of the degree of polymerization in PJ3, while the chain 
length, the branch amounts, and aggregate sizes increased, as evidenced by the rinsed percentage of carbon in PJ3.

Table 1. Wavelength Dispersive X-ray Spectroscopy (WDS) measurements of the compositions in wt.\% of PJ1, PJ2, and PJ3.

\begin{tabular}{cccc}
\hline Samples & $\mathbf{N}$ & $\mathbf{C}$ & $\mathbf{O}$ \\
\hline PJ1 & $1.24 \pm 0.02$ & $46.17 \pm 0.09$ & $7.98 \pm 0.88$ \\
PJ2 & $1.65 \pm 0.18$ & $63.61 \pm .0 .94$ & $12.93 \pm 0.97$ \\
PJ3 & $1.92 \pm 0.14$ & $69.87 \pm 0.84$ & $12.76 \pm 0.76$ \\
\hline
\end{tabular}

\subsection{Determination of Esterification Degree}

The degree of methoxylation of pectins is an important property in food processing systems due to its effect on functional properties such as gelling and solubility [33]. Moreover, it allows classifying pectins into two types: High-methoxyl (HM) form, characterized by a percentage of esterified groups greater than 50\%, and low-methoxyl (LM) form, in which the percentage of esterified carboxyl groups was less than $50 \%$. The degree of esterification of pectins from jujubes at three stages of harvesting $(\mathrm{H} 1, \mathrm{H} 2$, and $\mathrm{H} 3$ ) was determined by both classical titrimetric method (esterification degree determined by titration method, DE) and instrumental FTIR method (esterification degree determined by instrumental FTIR method, DM) (Figure 3). The degree of esterification, regardless of the method used, exhibited a significant increase as maturation proceeds. The titrimetric values for DE of pectins increased from $40.8 \%$ in $\mathrm{H} 1$ to $53.6 \%$ in $\mathrm{H} 3$. The instrumental technique, based on FTIR spectroscopy, provided slightly higher values for $\mathrm{H} 1$ (44.3\%) and slightly lower values for H3 $(50.9 \%)$, compared to the corresponding results of the titrimetric analysis. In both cases, statistical analysis showed that pectin degree of methoxylation from $\mathrm{H} 1$ jujubes is significantly lower than others. Each sample was analyzed in triplicate by both titrimetric and instrumental methods and the results are given as means \pm standard deviation.

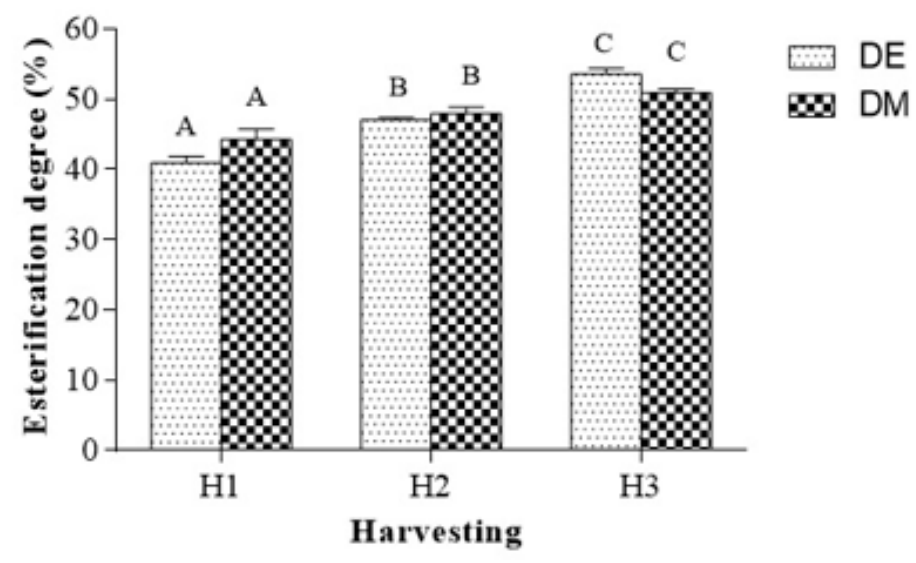

Figure 3. Effects of harvesting $(\mathrm{H} 1, \mathrm{H} 2$, and $\mathrm{H} 3)$ on esterification degree determined by titrimetric (esterification degree determined by titration method, DE) and instrumental methods (esterification degree determined by instrumental FTIR method, DM). Error bars represent standard deviation $(\mathrm{n}=3)$. Values with the same letter are not significantly different, while values with different letters are significantly different (DE: $\mathrm{H} 1$ vs. $\mathrm{H} 2{ }^{* *} p<0.01, \mathrm{H} 1$ vs. $\mathrm{H} 3,{ }^{* * * *} p<0.0001, \mathrm{H} 2$ vs. $\mathrm{H} 3{ }^{* *} p<0.01$; DM: $\mathrm{H} 1$ vs. $\mathrm{H} 2,{ }^{* *} p<0.01, \mathrm{H} 1$ vs. H3, ${ }^{* *} p<0.01, \mathrm{H} 2$ vs. H3, not significant, ns).

\subsection{Evolution of $p H$ and Kefir Weight during Heterolactic Fermentation}

At time $0 \mathrm{~h}$, before inoculation with kefir grains, the average whole milk $\mathrm{pH}$ was 6.7. As the fermentation progressed, the $\mathrm{pH}$ of kefir-added milk (control) decreased as a result of the growth of lactic acid bacteria and lactic acid production [34,35]: The initial value of $\mathrm{pH}$ was reduced by 
$38.3 \%$ up to the average value of $4.13 \pm 0.05$ after $24 \mathrm{~h}$ and by $42.7 \%$ to $3.84 \pm 0.05$ after $48 \mathrm{~h}$ (Figure 4). In pectin-supplemented kefirs (PJ1K, PJ2K, PJ3K), the $\mathrm{pH}$ value was $3.73 \pm 0.02$ for $\mathrm{PJ} 1 \mathrm{~K}, 3.97 \pm 0.02$ for PJ2K, and $4.01 \pm 0.02$ for PJ3K, after $24 \mathrm{~h}$ of fermentation (day 0). Significant higher acidity $\left({ }^{* * *} p<0.0001\right)$ resulted in PJ1K, in PJ2K (** $\left.p<0.01\right)$, and in PJ3K $\left({ }^{*} p<0.05\right)$. After $48 \mathrm{~h}$ of fermentation, $\mathrm{pH}$ was still low in $\mathrm{PJ} 1 \mathrm{~K}\left({ }^{*} p<0.05\right)$ and $\mathrm{PJ} 2 \mathrm{~K}\left({ }^{*} p<0.05\right)$. Lastly, the results showed that the addition of the pectins from jujubes at three different harvesting periods influenced the $\mathrm{pH}$ of supplemented kefirs with respect to the control, obtaining statistically significant decline of $\mathrm{pH}$ in kefir-supplemented pectins especially in PJ1K after $24 \mathrm{~h}$ of fermentation $(p<0.0001)$.

a)

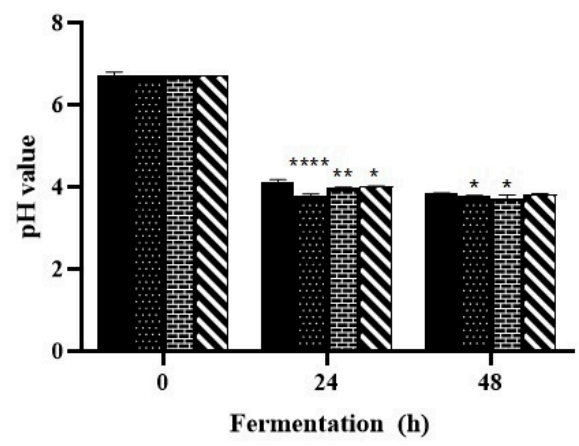

b)

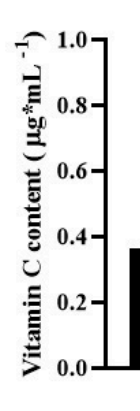

Figure 4. Evolution of $\mathrm{pH}$ (a) and vitamin C content (b) during fermentation, in control and pectin-supplemented kefirs. PJ1K: Kefir added with PJ1. PJ2K: Kefir added with PJ2. PJ3K: Kefir added with PJ3. Values represent the mean of three independent experiments (each done in triplicate) \pm standard deviation. Asterisks on the bars indicate that mean values were statistically different from the control, while asterisks on the dashes indicate differences among different treatments or the same treatment at different time points $\left({ }^{*} p<0.05,{ }^{* *} p<0.01,{ }^{* * *} p<0.001\right.$, and $\left.{ }^{* * *} p<0.0001\right)$.

Kefir grains are a cluster of microorganisms that make a complex microbiota which coexists in an exopolysaccharide matrix called kefiran, produced by Lactobacillus kefiranofaciens. As the cell growth and kefiran production rate is increased when L. kefiranofaciens is grown under the conditions created by yeasts [36], the increase in weight of the kefir grains was taken into account to confirm the amplified activity of the bacteria, although it is not correlated with the production of vitamin $\mathrm{C}$. The data obtained (Table 2) showed that the greatest weight gain was recorded for the PJ1K, in which the kefir grains are about 1.5 times heavier than the starting grains, witnessing the greatest activity of L. kefiranofaciens stimulated by the yeast in kefir sample added with pectins from green jujubes.

Table 2. Kefir weight in all fermented samples, expressed in g.

\begin{tabular}{cccc}
\hline Samples & $\mathbf{0 ~ h}$ & $\mathbf{2 4} \mathbf{h}$ & $\mathbf{4 8} \mathbf{h}$ \\
\hline Control & $1.01 \pm 0.01$ & $1.65 \pm 0.01$ & $1.95 \pm 0.01$ \\
PJ1 & $1.01 \pm 0.01$ & $2.60 \pm 0.03$ & $2.10 \pm 0.04$ \\
PJ2 & $1.04 \pm 0.06$ & $1.60 \pm 0.02$ & $1.46 \pm 0.05$ \\
PJ3 & $1.01 \pm 0.01$ & $1.40 \pm 0.01$ & $1.51 \pm 0.06$ \\
\hline
\end{tabular}

Values represent the mean of three independent measurements (each done in triplicate) \pm standard deviation.

\subsection{Vitamin C Content during Heterolactic Fermentation}

Recently, functional and bio-fortified foods are receiving great interest around the world as demonstrated by their huge market size. Functional foods are a fashion trend for the industrialized countries to keep health status and to prevent chronic disease, while in low-income countries, bio-fortified foods are a necessity to reach the health status and to prevent malnutrition and infectious diseases [37]. Among functional foods, fermented ones had longer storage life and improved nutritional 
values compared to their unfermented equivalents, making this form of food processing a popular technique. Kefir has a low production cost, can be produced at home, and can be easily incorporated into the diet. During the kefir fermentation process, approximately $30 \%$ of the lactose from milk is hydrolyzed by the $\beta$-galactosidase enzymes, turning lactose into glucose and galactose. Furthermore, bacteria present in kefir convert glucose into lactic acid, which causes $\mathrm{pH}$ reduction and increases in consistency. In this context, kefir is a good option for lactose-intolerant individuals [38]. In addition, it is known that the fermentation induced by kefir has significant influences on vitamin content [12]. We found that whole milk does not contain vitamin $C$ and, therefore, it has been used as a raw material in which to carry out all the experiments in order to better verify any positive influence of pectins on the production of vitamin C.

Our study showed that the addition of pectins enhanced the production of vitamin $C$; the content of vitamin $C$ was quantified in the control and pectin-supplemented kefirs during fermentation $(24 \mathrm{~h}$ and $48 \mathrm{~h}$ ) by HPLC (Figure 4). In the control, this vitamin reached a level of $0.36 \pm 0.01 \mu \mathrm{g} \cdot \mathrm{mL}^{-1}$ at $24 \mathrm{~h}$ of fermentation, while in all pectin-supplemented kefirs a higher content of vitamin $\mathrm{C}$ was detected: Ascorbic acid content was $0.83 \pm 0.01 \mu \mathrm{g} \cdot \mathrm{mL}^{-1}$ in $\mathrm{PJ} 1 \mathrm{~K}, 0.60 \pm 0.02 \mu \mathrm{g} \cdot \mathrm{mL}^{-1}$ in $\mathrm{PJ} 2 \mathrm{~K}$, and $0.53 \pm 0.01 \mu \mathrm{g} \cdot \mathrm{mL}^{-1}$ in $\mathrm{PJ} 3 \mathrm{~K}$ at $24 \mathrm{~h}$ of fermentation. All the results obtained were significantly different compared to the control (*** $p<0.0001)$. In particular, the addition of pectins from H1 jujubes $(\mathrm{PJ} 1 \mathrm{~K})$ resulted in a quantitatively higher vitamin $\mathrm{C}$ level compared to all the other treatments (PJ2K and $\mathrm{PJ} 3 \mathrm{~K})$, after $24 \mathrm{~h}$ fermentation $\left({ }^{* * *} p<0.0001\right)$. The results related to the production of vitamin $\mathrm{C}$ after $24 \mathrm{~h}$ of fermentation were in agreement with the $\mathrm{pH}$ values reached in $\mathrm{PJ} 1 \mathrm{~K}$, after the same time: PJ1 kefir with the highest vitamin level was also the one with the most acidic $\mathrm{pH}$ value $(3.73 \pm 0.02)$. After $48 \mathrm{~h}$ fermentation, the content of vitamin C in PJ1K decreased compared to that obtained after $24 \mathrm{~h}$ fermentation, reaching a final value of $0.69 \pm 0.04 \mu \mathrm{g} \cdot \mathrm{mL}^{-1}$ at the end of the period studied $\left({ }^{* *} p<0.01\right)$, but, in any case, it was significantly higher than the control $\left({ }^{* * *} p<0.0001\right)$, as well as than PJ2K $\left({ }^{*} p<0.05\right)$ and PJ3K $\left({ }^{* *} p<0.001\right)$.

In PJ2K and PJ3K, vitamin C content remained constant compared to that obtained after $24 \mathrm{~h}$ fermentation. Also, kefir samples were added with higher amount of pectins, but after fermentation the content of vitamin $C$ was not increased (data not shown), if compared to the content found in kefir sample supplemented by $0.25 \mathrm{mg} \cdot \mathrm{mL}^{-1}$ of pectins, which represents the maximum amount used in all experiments. The results showed that the vitamin $C$ content, which was higher in kefir supplemented with pectins from green jujube, was correlated to the pectin methoxylation degree: The production of vitamin $C$ was greater if the methoxylation degree was lower. This correlation would seem to support the hypothesis [39] according to which the yeasts present in kefir grains can assimilate galactose and may produce vitamin $C\left(0.36 \pm 0.01 \mu \mathrm{g} \cdot \mathrm{mL}^{-1}\right.$ in the control). In fact, during fermentation an interaction between yeasts and LAB occurs, suggesting that the yeasts could provide vitamins, amino acids, and growth factors for bacteria, while the bacterial end products could be used by the yeasts as an energy source. Yeasts stimulated the LAB through production of carbon dioxide, pyruvate, propionate, and succinate, and some LAB release galactose into the medium as a by-product of lactose metabolism, which may be assimilated by yeast. In pectin-supplemented kefir, galactose is not only that produced by LAB, but also that deriving from pectins, which, especially when characterized by a lower degree of methoxylation, are more easily hydrolyzable by enzymes and provide the individual units of galactopyranosyluronic acid as a substrate for yeasts. In fact, the hydrolysis of the glycosidic bonds in the main pectin backbone occurs more easily if the monosaccharide units are demethylated, as evidenced by the hydrolytic activity of the polygalacturonases. These actions would explain why the addition of pectins caused an increase in the production of vitamin $C\left(0.83 \pm 0.01 \mu \mathrm{g} \cdot \mathrm{mL}^{-1}\right.$ in PJK1) during heterolactic fermentation; this production decreases proportionally as the degree of methoxylation increases $\left(0.53 \pm 0.01 \mu \mathrm{g} \cdot \mathrm{mL}^{-1}\right.$ in PJK3). Also, it is possible to establish a correlation between increased production of vitamin $\mathrm{C}$ and decrease in supplemented kefir $\mathrm{pH}$ during fermentation, compared to the control. Vitamin C production by yeasts would seem to enhance the growth of lactic acid bacteria, which also produce lactate. Then, lactic acid bacteria diminish pH rapidly (3.73 \pm 0.02 for PJ1K) 
with respect to control $(4.13 \pm 0.05)$, while lactate accumulation until this production is inhibited and components that are responsible for the flavor, such as acetaldehyde, are produced along with aromas of fermented milk.

Kefir products are considered predominantly lactic fermentations by lactic acid bacteria and yeast $[40,41]$. The changes of LAB and yeasts were estimated at two time points (24 and $48 \mathrm{~h}$ ) (Figure 5).
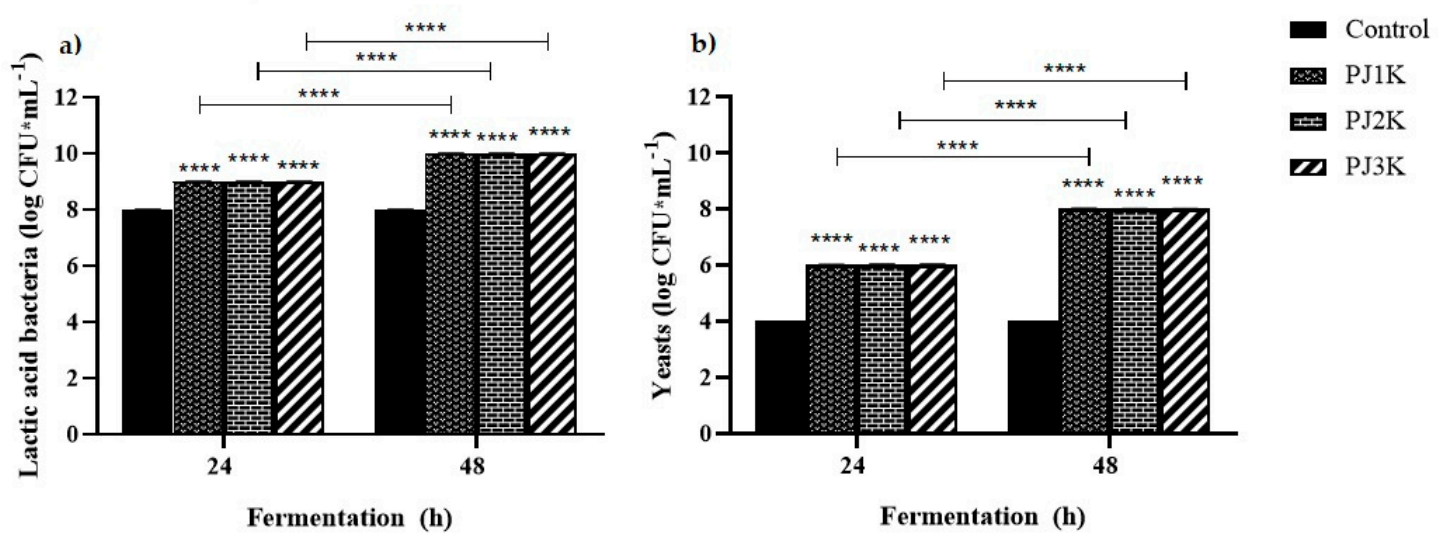

Figure 5. Cell counts of lactic acid bacteria (a) and yeasts (b) populations in kefir samples supplemented with (or without, used as control) $0.25 \mathrm{mg} \cdot \mathrm{mL}^{-1}$ of PJ1 (PJ1K), PJ2 (PJ2K), and PJ3 (PJ3K) during fermentation. Values represent the means of three independent experiments (each done in duplicate) \pm standard deviation. Asterisks on the bars indicate that mean values were statistically different from the control, while asterisks on the dashes indicate differences among the same treatment at different time points $\left({ }^{* * * *} p<0.0001\right)$.

The LAB reached the stationary phase after $24 \mathrm{~h}$, since at $48 \mathrm{~h}$ similar result was achieved in terms of count of colony-forming unit (CFU), but the population was significantly different with respect to control and, as such, continues to be an energy source for yeasts. On the other hand, the yeast counts gradually increased also at $48 \mathrm{~h}$ of fermentation in the presence of pectins. Nevertheless, the production of vitamin C did not increase compared to the level obtained after $24 \mathrm{~h}$ in the kefir sample supplemented with green jujubes. This result suggested that jujube pectins ensure the survival of LAB and enhanced yeast growth, without further stimulation for these to produce vitamin C. After $24 \mathrm{~h}$ it would seem that bacteria and yeasts reach an equilibrium symbiosis that does not bring further changes in the content of vitamin $\mathrm{C}$, in the $\mathrm{pH}$ values, or in the amount of product kefiran. Interestingly, we did not observe any differences either in LAB or in yeast counts among the kefir samples treated with pectins from the different ripening stages. The difference of vitamin $C$ content in the kefir samples supplemented with pectins from all three collections is influenced by the degree of methoxylation which, if elevated, inhibits the hydrolytic action of the enzymes on the skeleton of polygalacturonic acid, such as galactose source for yeasts. These results support our hypothesis regarding the crucial role of pectins in the increased production of vitamin C. In particular, we can rationalize that all pectins stimulate the growth of yeasts during the first $24 \mathrm{~h}$, but the pectins from jujubes at the first stage of ripening (PJ1), characterized by a lower methoxylation degree, act as the best substrates for yeasts, thus yielding to the highest amount of vitamin $\mathrm{C}$.

\section{Materials and Methods}

\subsection{Standards, Solvents, and Reagents}

All chemicals and reagents, including a 99.7\% purity ascorbic acid standard, were purchased from Sigma-Aldrich S.p.a. (Milan, Italy). Analytical grade solvents were bought from VWR International S.r.l. (Milan, Italy). 


\subsection{Milk Samples}

Different commercial cow milk samples (Granarolo, Bologna, Italy) were purchased from a local market including pasteurized whole, partially skimmed, and skimmed. The milk samples were analyzed to establish the one with less or no vitamin $C$ content to be used in the heterolactic fermentation. Screening of commercial milks for the determination of the vitamin $C$ content was carried out by HPLC analyses.

\subsection{Kefir Grains}

Kefir grains were obtained from Kefiralia (Arrasate, Gipuzkoa, Spain) and were composed of $10^{9} \mathrm{CFU} / \mathrm{g}$ of LAB (Lactococcus lactis subsp. lactis, Lactococcus lactis subsp. lactis biovar diacetylactis, Lactococcus lactis subsp. cremoris, Leuconostoc mesenteroides subsp. cremoris, Lactobacillus kefyr), Candida kefyr, and Saccharomyces unisporus subsp., as declared by the producer. Microorganisms exist in a matrix composed of polysaccharide, referred to as kefiran [42,43]. The grains were washed three times with deionized water and then were placed in a nonhermetically sealed glass container and were grown at room temperature in $1 \mathrm{~L}$ of milk, without stirring. The medium was changed daily. Kefir grains to be used were separated from kefir-fermented milk by filtration with a plastic sieve and washed with cold running water.

\subsection{Plant Materials}

The jujube fruits were harvested in the locality of Rombiolo (latitude: $38^{\circ} 35^{\prime} 34^{\prime \prime} 08 \mathrm{~N}$, longitude: $16^{\circ} 0^{\prime} 9^{\prime \prime} 00 \mathrm{E}$, Calabria, Southern Italy), in September-October 2017. The drupes were picked up from the same area three times, at a distance of 15 days from each other. The fruits, which have a round shape, changed dimensions and colors during this harvest period (Figure 6). The thin, edible skin was green in color at the first harvesting (H1), when the fruits are immature, but as ripening continued, the skin color progressed from a yellow-green stage with mahogany-colored spots (second harvesting, $\mathrm{H} 2)$ to half red-half creamy. The fruits collected at the third harvesting ( $\mathrm{H} 3$, almost completely red) had a crisp texture. This aspect indicated that pectin-depolymerizing enzymes, such as polygalacturonases, had not yet acted on the cell walls of the fruit, causing its softening. Fruit size was calculated by averaging the measurements of 20 randomly picked fruits. In H1 fruit length and diameter were $19 \pm 1$ and $4.7 \pm 0.5 \mathrm{~mm}$, respectively; in $\mathrm{H} 2,19.7 \pm 0.4 \mathrm{~mm}$ of length and $6.5 \pm 0.2 \mathrm{~mm}$ of diameter; and in $\mathrm{H} 3,21.2 \pm 0.7 \mathrm{~mm}$ of length and $7.8 \pm 0.2 \mathrm{~mm}$ of diameter. The fruits at all harvesting periods were freeze-dried (Telstar freeze-dryer, model Cryodos, Terrassa, Spain), followed by removing of the seeds. Dried jujubes were ground to a fine powder using a 60-mesh screen (particle size equal to $250 \mu \mathrm{m}$ ) and stored at $-20^{\circ} \mathrm{C}$, before the extraction. All extractions were performed in triplicate using three samples selected for each harvesting period. The results are expressed on a dry weight (DW) basis.

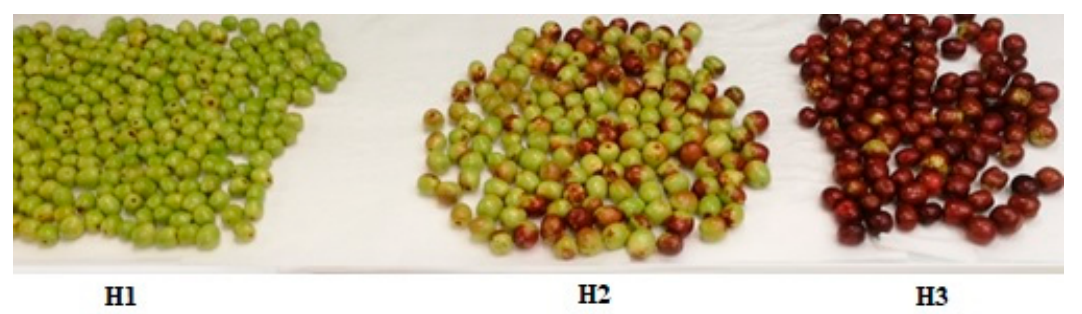

Figure 6. Division of harvesting stages (H1 to H3) according to appearance of jujube fruit. Harvesting stages of jujube fruits were characterized by different colors and sizes: H1, green stages; $\mathrm{H} 2$, yellow and green stage with mahogany-colored spots; H3, all-red ripening stage.

\subsection{Extraction of Pectins}

Pectins from jujubes were extracted following a previously reported method [44]. Jujube flour $(2 \mathrm{~g})$ was suspended in 10\% $(w / v)$ citric acid solution (sample-to-solution ratio 1:20 w/v) adjusting 
the $\mathrm{pH}$ to 2. Afterwards, the mixture was kept under reflux at $90^{\circ} \mathrm{C}$ with magnetic stirring for $1 \mathrm{~h}$. After cooling, the mixture was centrifuged at $5000 \times g$ for $30 \mathrm{~min}$ (Universal 320, Hettich Zentrifugen, Merck, Italy). Then, absolute ethanol $(1: 1 \mathrm{v} / \mathrm{v})$ was added to the supernatant and kept at $4{ }^{\circ} \mathrm{C}$ for $16 \mathrm{~h}$ in order to precipitate the pectins. The precipitate was recovered after centrifugation, washed with absolute ethanol, solubilized in distilled water, treated with acetone in the ratio of 1:1, and kept at $4{ }^{\circ} \mathrm{C}$ for $12 \mathrm{~h}$ to remove undesired pectin color [26]. The precipitated pectins were isolated by centrifugation at $5000 \times g$ for $15 \mathrm{~min}$ and were dried under vacuum. Extractions were performed in triplicate and data of pectin content recovered are expressed as means \pm standard deviation. The pectins from jujubes of the first, second, and third harvestings were designated as PJ1, PJ2, and PJ3, respectively. All samples were characterized by FTIR and SEM.

\subsection{FTIR Spectroscopic Analysis}

FTIR spectroscopy of isolated PJ samples was carried out using a Bruker ALPHA FTIR spectrometer (Billerica, MA, USA) with $\mathrm{KBr}$ method in the wavenumber range of $4000-400 \mathrm{~cm}^{-1}$ [44]. Dried samples were ground in an agate mortar with $\mathrm{KBr}$ in 1:40 ratio and pressed into pellets. Twelve scans were performed with a resolution of $4 \mathrm{~cm}^{-1}$. All measurements were acquired in triplicate.

\subsection{Scanning Electron Microscopy}

The morphological analysis of the samples was acquired by a scanning electron microscope (SEM) (Field Emission SEM FEI Quanta 200, Thermo Fisher Scientific, Hillsboro, OR, USA) and Electron Probe Micro Analyzer (EPMA)-JEOL-JXA 8230t (Kyoto, Japan).

Before analysis, the surface of the samples was coated by a 5-nm-thick layer of carbon, using a Carbon Coater QUORUM Q150T-ES. The SEM analysis conditions were the following: high voltage (HV): $15 \mathrm{kV}$; probe current: 10-20 nanoAmpere (nA); working distance: $11 \mathrm{~mm}$; image: back-scattered electrons' technique (BSE) signal; detector image: Solid state detector (SSD), Everhart-Thornley detector (Scattered electron, SE); image size: $2560 \times 1920$ pixel.

SE signal was used to acquire morphological pictures while BSE signal was used for crystal observation.

The WDS analysis conditions were the following (Spectrometers WDS XCE type and X type): HV $15 \mathrm{kV}$, probe current $10 \mathrm{nA}$, and working distance of $11 \mathrm{~mm}$. For WDS analysis, all experiments were carried out at room temperature $\left(22 \pm 1{ }^{\circ} \mathrm{C}\right)$ and, for each sample, three points were analyzed to determinate the average value for $\mathrm{N}, \mathrm{C}$, and $\mathrm{O}$ content.

\subsection{Determination of Esterification Degree}

The esterification degree of pectins is one of the most important properties of pectins, determined by the potentiometric titration method (DE) and confirmed by the instrumental FTIR method (DM).

\subsubsection{Titration Method}

The esterification degree of pectins was determined by titrimetric method, as previously described [45]. Dried pectin $(20 \mathrm{mg})$ sample was weighed in a bottle for titration, wetted with ethanol, dissolved in $5 \mathrm{~mL}$ of distilled water, and heated at $45^{\circ} \mathrm{C}$, under magnetic stirring, until the pectin dissolved completely. The resulting solution was added of 3 drops of phenolphthalein and titrated with $0.01 \mathrm{~N} \mathrm{NaOH}$ till the solution color changed to pale pink (V1). This initial titration volume indicated the number of free carboxy groups.

Then, polygalacturonic acid was neutralized by adding $3 \mathrm{~mL}$ of $0.01 \mathrm{~N} \mathrm{NaOH}$ followed by stirring at room temperature for $2 \mathrm{~h}$ in order to saponify the esterified carboxy groups of the polymer. $\mathrm{NaOH}$ was neutralized by adding $3 \mathrm{~mL}$ of $0.01 \mathrm{~N} \mathrm{HCl}$ to the solution and then the excess $\mathrm{HCl}$ was titrated with $0.01 \mathrm{~N} \mathrm{NaOH}$ after the addition of three drops of phenolphthalein. The sample was 
shaken until pale-pink color appeared, and the titration volume was recorded (V2, indicating the number of esterified carboxy groups). The DE was calculated from the following formula:

$$
\% \mathrm{DE}=[\mathrm{V} 2(\mathrm{~mL}) / \mathrm{V} 1(\mathrm{~mL})+\mathrm{V} 2(\mathrm{~mL})] \times 100 .
$$

\subsubsection{Instrumental FTIR Method}

In this methodology, the degree of methoxylation (DM) was determined using the FTIR spectra recorded for the characterization of pectins [45]. In particular, the bands at $1748 \mathrm{~cm}^{-1}$ (arising from the $v \mathrm{C}=\mathrm{O}$ from ester group) and at $1647 \mathrm{~cm}^{-1}$ (due to the $v \mathrm{COO}^{-}$from the carboxylate group) were used to determine the $\% \mathrm{DM}$, according to the following equation:

$$
\% \mathrm{DM}=\left[\mathrm{A} 1748 \mathrm{~cm}^{-1} /\left(\mathrm{A} 1647 \mathrm{~cm}^{-1}+\mathrm{A} 1748 \mathrm{~cm}^{-1}\right)\right] \times 100 .
$$

\subsection{Heterolactic Fermentation Procedure}

Kefir samples were prepared at two different fermentation times ( 24 and $48 \mathrm{~h}$ ) by inoculating whole cow milk with kefir grains. Kefir grains $(1 \mathrm{~g})$ were placed in a glass container, in which $10 \mathrm{~mL}$ of cow milk was dispensed. The glass container was not hermetically closed by para film, on which holes were made by micro-needle device (fermentation produces $\mathrm{CO}_{2}$ ). Fermentation was carried out at room temperature (approximately, $20-25^{\circ} \mathrm{C}$ ), in aerobic conditions, and without shaking. Fermented milk with kefir grains (named as $0 \mathrm{~h}$ sample) was used as a control. The same protocol was applied to the milk samples containing kefir grains supplemented with pectins from jujubes of all harvesting $\left(0.25 \mathrm{mg} \cdot \mathrm{mL}^{-1}\right)$ : PJ1K (kefir supplemented with pectin from jujube of first harvesting), PJ2K (kefir supplemented with pectin from jujube of second harvesting), and PJ3K (kefir supplemented with pectin from jujube of third harvesting). Three independent, biological replicates were carried out for each sample. The fermentation product (i.e., kefir) was separated from the kefir grains by filtration with a plastic sieve. The $\mathrm{pH}$ was measured in all supernatants with an electrode $\mathrm{pH}$-meter (Hanna Instruments) during fermentation (0, 24, and $48 \mathrm{~h}$ ). Kefir grains in all fermented samples were weighed at the end of the experiment, after centrifugation at $3000 \mathrm{rpm}$ for $10 \mathrm{~min}$ at $4{ }^{\circ} \mathrm{C}$.

\subsection{Vitamin C Extraction and HPLC Conditions}

Vitamin C contents of whole milk, kefir, and pectin-supplemented kefirs were determined by HPLC analyses, as described previously [45]. Milk and kefir supernatants $(2 \mathrm{~mL})$ were mixed with $1.25 \mathrm{~mL}$ of acetic acid, diluted with distilled water $(10 \mathrm{~mL})$, vortexed for $10 \mathrm{~s}$, and centrifuged at $5000 \times g$ for $10 \mathrm{~min}$ to separate coagulated caseins. The supernatants were filtered through sterile $0.45-\mu \mathrm{m}$ pore-size filters (Millipore, Millex-GV, Darmstadt, Germany), to remove cells released from the kefir grains, into amber vials and injected directly into the HPLC system.

HPLC analyses were carried out using a high performance liquid chromatography-diode array detector (HPLC-DAD) system (Shimadzu, Kyoto, Japan), equipped with two LC-20A pumps and an SPD-M20A DAD detector; the column used was a mediterranea SEA 18 (Teknokroma, Barcelona, Spain) $\left(250 \mathrm{~mm} \times 0.46 \mathrm{~mm}_{\text {id }}, 5-\mu \mathrm{m}\right.$ particle size). The analyses were carried out at a constant flow rate of $0.7 \mathrm{~mL} \cdot \mathrm{min}^{-1}$ using a mobile phase of $\mathrm{H}_{2} \mathrm{SO}_{4}$ in deionized water at $\mathrm{pH}$ of 2.5 . The injection volume was $20 \mu \mathrm{L}$, the detection wavelength $254 \mathrm{~nm}$, and the run time was $40 \mathrm{~min}$. Data were integrated and analyzed using the Shimadzu Class-VP Chromatography Laboratory Automated Software system. Quantitative analysis was carried out by the external standard method using standard solutions at a concentration range of $10-500 \mu \mathrm{g} \cdot \mathrm{mL}^{-1}$. Determination of coefficients obtained from these calibration curves were linear over the range studied $\left(R^{2}=1\right)$.

\subsection{Bacterial and Yeast Counts}

Lactic acid bacteria and yeast counts were carried out in duplicate on kefir samples added (or not, control) with pectins from jujubes at different ripening stages, at two time points ( 24 and $48 \mathrm{~h}$ ), according 
to a known protocol [11]. Samples were diluted with sterile saline solution $(1: 10,000)$ and plated on sterile bromocresol purple (BCP) agar (Condalab, Madrid, Spain) at $37^{\circ} \mathrm{C}$ for 3 days to determine LAB, or on sterile potato dextrose agar (Condalab, Madrid, Spain) at $24^{\circ} \mathrm{C}$ for 5 days to determine yeast counts.

\subsection{Statistical Analysis}

The experimental data of methoxylation degree (DM and DE), $\mathrm{pH}$, vitamin $\mathrm{C}$ content, and LAB and yeast counts of kefir samples during fermentation are presented as mean values \pm standard deviations. Each experiment was replicated three times. Statistical differences among all prepared kefirs (control and PJ1K, PJ2K, PJ3K) were evaluated by two-way ANOVA followed by Holm-Sidak's multiple comparisons' post hoc test. The significance was established at $p$ values $<0.05\left(^{*}\right), p<0.01\left({ }^{* *}\right)$, and $p<0.0001(* * *)$.

\section{Conclusions}

In the present work, we characterized the pectins from jujubes at three different degrees of ripeness (PJ1, PJ2, and PJ3) by means of FTIR and SEM. Pectins from jujubes at the first stage of ripening (PJ1) were characterized by the lowest methoxylation degree, as it was confirmed by instrumental as well as titrimetric methods. The addition of all pectin samples to milk containing kefir grains (the control) influenced the acidity and vitamin $\mathrm{C}$ amount in kefir beverages, prepared by inoculating whole cow milk, not containing vitamin $C$, with kefir grains. Moreover, the amount of vitamin $C$ content in kefir was found to depend on the ripening stage of the fruits as kefir obtained by the addition of PJ1 $(\mathrm{PJ} 1 \mathrm{~K})$ resulted in a quantitatively higher vitamin $\mathrm{C}$ level compared to all the other samples (PJ2K and $\mathrm{PJ} 3 \mathrm{~K})$, after 24 and $48 \mathrm{~h}$ fermentation. In particular, the amount of vitamin C in PJ1K was 2.3 times higher than that recorded in the control. This result fit well with the $\mathrm{pH}$ value observed, which was the lowest value among all kefir samples $(3.73 \pm 0.02)$. To clarify the role of microorganisms on the production of vitamin $\mathrm{C}$ and $\mathrm{pH}$ values of the samples during fermentation, an estimation of LAB and the yeast population at 24 and $48 \mathrm{~h}$ was carried out. The yeast counts gradually increased also at $48 \mathrm{~h}$ of fermentation in the presence of all pectins. The results supported the hypothesis that all pectins stimulate the growth of yeasts during the first $24 \mathrm{~h}$, possibly supplying them galactose as a substrate. No differences were observed either in LAB or in yeast counts among the kefir samples treated with pectins from the different ripening stages. The difference of vitamin $C$ content in the kefir samples can be influenced by the degree of methoxylation which, if elevated, inhibits the hydrolytic action of the enzymes on the skeleton of polygalacturonic acid. Then, pectins from jujubes at the first stage of ripening (PJ1), characterized by a lower methoxylation degree, act as the best substrates for yeasts, thus yielding the highest amount of vitamin $\mathrm{C}$. Hence, this study showed that pectins from jujubes could be used to increase the amount of vitamin $C$ in kefir, although the final amount is far from being close to the recommended dietary intake. Further research is needed to possibly overcome this limitation.

Author Contributions: A.F. coordinated the work, and wrote and edited the manuscript; C.L.T. carried out the experiments; M.C.C. analyzed the data and revised the statistical analyses; P.C. conducted morphological characterization of glucans; R.C. facilitated the experiments; P.P. revised the manuscript; and E.C. designed the research and conducted biological experiments. All authors have read and agreed to the published version of the manuscript.

Funding: This research received no external funding.

Conflicts of Interest: The authors declare no conflict of interest. 


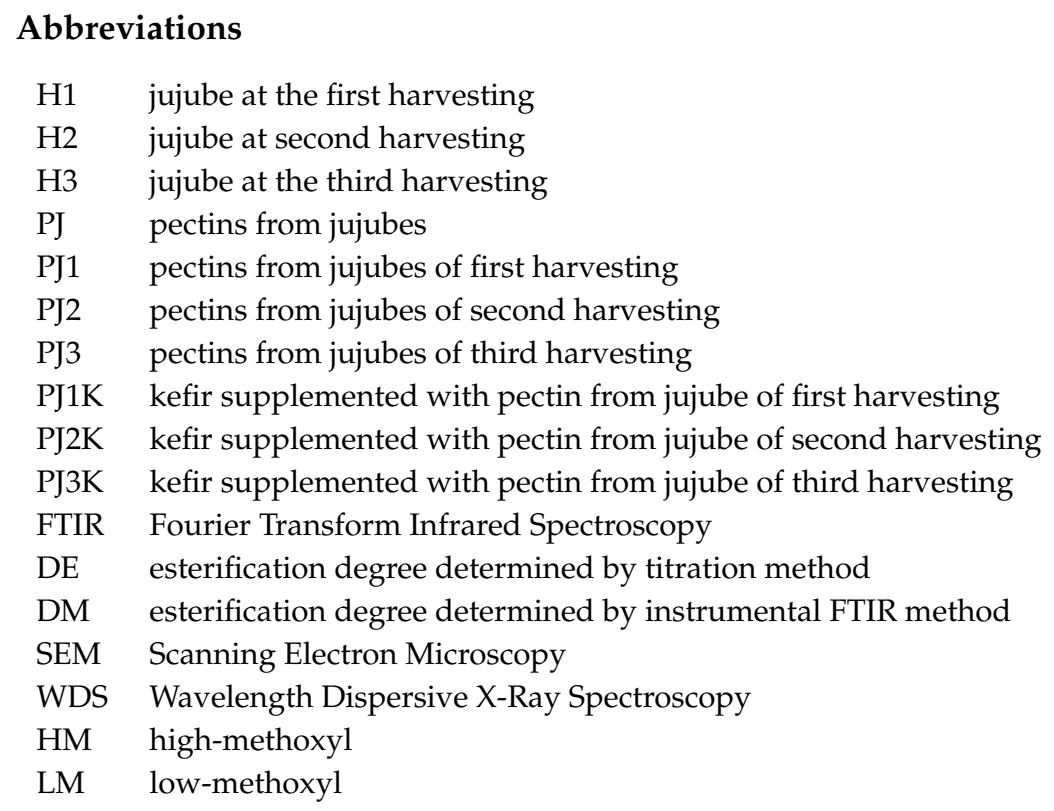

\section{References}

1. Inbaraj, B.S.; Chen, B.H. Polysaccharide Composition in Chinese Dates (Jujubes) and Health Benefits. In Chinese Dates-A Traditional Functional Food, 1st ed.; Li, D., Ye, X., Jiang, Y., Eds.; CRC Press: Boca Raton, FL, USA, 2016; pp. 167-197, ISBN 978-1-4987-0358-1.

2. Cione, E.; La Torre, C.; Cannataro, R.; Caroleo, M.C.; Plastina, P.; Gallelli, L. Quercetin, Epigallocatechin Gallate, Curcumin, and Resveratrol: From Dietary Sources to Human MicroRNA Modulation. Molecules 2019, 25, 63. [CrossRef] [PubMed]

3. Plastina, P.; Bonofiglio, D.; Vizza, D.; Fazio, A.; Rovito, D.; Giordano, C.; Barone, I.; Catalano, S.; Gabriele, B. Identification of bioactive constituents of Ziziphus jujube fruit extracts exerting antiproliferative and apoptotic effects in human breast cancer cells. J. Ethnopharmacol. 2012, 140, 325-332. [CrossRef] [PubMed]

4. Fazio, A.; La Torre, C.; Caroleo, M.C.; Caputo, P.; Plastina, P.; Cione, E. Isolation and Purification of Glucans from an Italian Cultivar of Ziziphus jujuba Mill. and In Vitro Effect on Skin Repair. Molecules 2020, 25, 968. [CrossRef] [PubMed]

5. Plastina, P.; Gabriele, B. Phytochemical Constituents and Health Benefits of Jujubes. In Chinese Dates-A Traditional Functional Food, 1st ed.; Li, D., Ye, X., Jiang, Y., Eds.; CRC Press: Boca Raton, FL, USA, 2016; pp. 155-175, ISBN 978-1-4987-0358-1.

6. Li, J.; Fan, L.; Ding, S.; Ding, X. Nutritional composition of five cultivars of Chinese jujube. Food Chem. 2007, 103, 454-460. [CrossRef]

7. Naqash, F.; Masoodi, F.A.; Rather, S.A.; Wani, S.M.; Gani, A. Emerging concepts in the nutraceutical and functional properties of pectin-A Review. Carbohydr. Polym. 2017, 168, 227-239. [CrossRef] [PubMed]

8. Thiraviam, V.; Mahejibin, K. Role of Pectin in Food Processing and Food Packaging. In Pectins-Extraction, Purification, Characterization and Applications, 22nd ed.; Masuelli, A., Ed.; IntechOpen Ltd.: London, UK, 2020; pp. 1237-1257, ISBN 978-1-78984-072-8.

9. Chung, W.S.F.; Meijerink, M.; Zeuner, B.; Holck, J.; Louis, P.; Meyer, A.S.; Wells, J.M.; Flint, H.J.; Duncan, S.H. Prebiotic potential of pectin and pectic oligosaccharides to promote anti-inflammatory commensal bacteria in the human colon. FEMS Microbiol. Ecol. 2017, 93, 127. [CrossRef]

10. Montanuci, F.D.; Pimentel, T.C.; Garcia, S.; Prudencio, S.H. Effect of starter culture and inulin addition on microbial viability, texture, and chemical characteristics of whole or skim milk Kefir. Ciência Tecnol. Alime. 2012, 32, 850-861. [CrossRef]

11. Oh, N.S.; Lee, H.A.; Myung, J.H.; Lee, J.Y.; Joung, J.Y.; Shin, Y.K. Effect of different commercial oligosaccharides on the fermentation properties in kefir during fermentation. Korean J. Food Sci. Anim. Resour. 2013, 33, 325-330. [CrossRef] 
12. Satir, G.; Guzel-Seydim, Z.B. How kefir fermentation can affect product composition? Small Ruminant Res. 2016, 134, 1-7. [CrossRef]

13. Garrote, G.L.; Abraham, A.G.; De Antoni, G.L. Chemical and microbiological characterisation of kefir grains. J. Dairy Res. 2001, 68, 639-652. [CrossRef]

14. Glibowski, P.; Kowaslka, A. Rheological, texture and sensory properties of kefir with high performance and native inulin. J. Food Eng. 2012, 111, 299-304. [CrossRef]

15. Glibowski, P.; Zielińska, E. Physicochemical and sensory properties of kefir containing inulin and oligofructose. Int. J. Dairy Technol. 2015, 68, 602-607. [CrossRef]

16. Piermaria, J.A.; de la Canal, M.L.; Abraham, A.G. Gelling properties of kefiran, a food-grade polysaccharide obtained from kefir grain. Food Hydrocoll. 2008, 22, 1520-1527. [CrossRef]

17. Mayo, B.; Aleksandrzak-Piekarczyk, T.; Fernández, M.; Kowalczyk, M.; Álvarez-Martín, P.; Bardowski, J. Updates in the metabolism of lactic acid bacteria. In Biotechnology of lactic acid bacteria. Novel applications; Mozzi, F., Raya, R.R., Vignolo, G.M., Eds.; Wiley-Blackwell: Hoboken, NJ, USA, 2010; pp. 3-33, ISBN 0813815835.

18. Heller, K.J. Probiotic bacteria in fermented foods: Product characteristics and starter organisms. Am. J. Clin. Nutr. 2001, 73, 374-379. [CrossRef] [PubMed]

19. Rosa, D.D.; Dias, M.M.S.; Grześkowiak, Ł.M.; Reis, S.A.; Conceição, L.L.; Peluzio, M.D.C.G. Milk kefir: Nutritional, microbiological and health benefits. Nutr. Res. Rev. 2017, 30, 82-96. [CrossRef]

20. Simova, E.; Beshkova, D.; Angelov, A.; Hristozova, T.; Frengova, G.; Spasov, Z. Lactic acid bacteria and yeasts in kefir grains and kefir made from them. J. Ind. Microbiol. Biot. 2002, 28, 1-6. [CrossRef]

21. Lopitz-Otsoa, F.; Rementeria, A.; Elguezabal, N.; Garaizar, J. Kefir: A symbiotic yeasts-bacteria community with alleged healthy capabilities. Rev. Iberoam. Micol. 2006, 23, 67-74. [CrossRef]

22. Di Matteo, A.; Sacco, A.; Anacleria, M.; Pezzotti, M.; Delledonne, M.; Ferrarini, A.; Frusciante, L.; Barone, A. The ascorbic acid content of tomato fruits is associated with the expression of genes involved in pectin degradation. BMC Plant. Biol. 2010, 10, 1-11. [CrossRef]

23. Hancock, R.D.; Viola, R. Improving the Nutritional Value of Crops through Enhancement of L-Ascorbic Acid (Vitamin C) Content: Rationale and Biotechnological Opportunities. J. Agric. Food Chem. 2005, 53, 5248-5257. [CrossRef]

24. Goncu, B.; Celikel, A.; Guler-Akin, M.B.; Akin, M.S. Some properties of kefir enriched with apple and lemon fiber. Mljekarstvo 2017, 67, 208-216. [CrossRef]

25. Demir, C.; Kinik, O.; Yerlikaya, O.; Acu, M. Effect of apple and lemon dietary fibers on some characteristics of low fat kefir. Milchwiss.-Milk Sci. Int. 2012, 67, 406-410.

26. Pinheiro, E.R.; Silva, I.M.D.A.; Gonzaga, L.V.; Amante, E.R.; Teófilo, R.F.; Ferreira, M.M.C.; Amboni, R.D.M.C. Optimization of extraction of high-ester pectin from passion fruit peel (Passiflora edulis Flavicarpa) with citric acid by using response surface methodology. Bioresour. Technol. 2008, 99, 5561-5566. [CrossRef] [PubMed]

27. Wang, H.; Chen, F.; Yang, H.; Chen, Y.; Zhang, L.; An, H. Effects of ripening stage and cultivar on physicochemical properties and pectin nanostructures of jujubes. Carbohydr. Polym. 2012, 89, 1180-1188. [CrossRef]

28. Szymanska-Chargot, M.; Zdunek, A. Use of FT-IR spectra and PCA to the bulk characterization of cell wall residues of fruits and vegetables along a fraction process. Food Biophys. 2013, 8, 29-42. [CrossRef] [PubMed]

29. Li, Q.; Xu, R.; Fang, Q.; Yuan, Y.; Cao, J.; Jiang, W. Analyses of microstructure and cell wall polysaccharides of flesh tissues provide insights into cultivar difference in mealy patterns developed in apple fruit. Food Chem. 2020, 321, 126707. [CrossRef]

30. Chylińska, M.; Szymanska-Chargot, M.; Zdunek, A. FT-IR and FT-Raman characterization of non-cellulosic polysaccharides fractions isolated from plant cell wall. Carbohydr. Polym. 2016, 154, 48-54. [CrossRef]

31. Deng, L.Z.; Pan, Z.; Zhang, Q.; Liu, Z.L.; Zhang, Y.; Meng, J.S.; Gao, Z.J.; Xiao, H.W. Effects of ripening stage on physicochemical properties, drying kinetics, pectin polysaccharides contents and nanostructure of apricots. Carbohydr. Polym. 2019, 222, 114980. [CrossRef]

32. Geerkens, C.H.; Nagel, A.; Just, K.M.; Miller-Rostek, P.; Kammerer, D.R.; Schweiggert, R.M.; Carle, R. Mango pectin quality as influenced by cultivar, ripeness, peel particle size, blanching, drying, and irradiation. Food Hydrocoll. 2015, 51, 241-251. [CrossRef]

33. Liu, L.; Fishman, M.L.; Hicks, K.B. Pectin in controlled drug delivery-A review. Cellulose 2007, 14, 15-24. [CrossRef] 
34. Delgado-Fernandez, P.; Corzo, N.; Lizasoain, S.; Olano, A.; Moreno, E.J. Fermentative properties of starter culture during manufacture of kefir with new prebiotics derived from lactulose. Int. Dairy J. 2019, 93, 22-29. [CrossRef]

35. Guzel-Seydim, Z.; Wyffels, J.T.; Seydim, A.C.; Greene, A.K. Turkish kefir and kefir grains: Microbial enumeration and electron microscobic observation. Int. J. Dairy Technol. 2005, 58, 25-29. [CrossRef]

36. Cheirsilp, B.; Shimizu, H.; Shioya, S. Enhanced kefiran production by mixed culture of Lactobacillus kefiranofaciens and Saccharomyces cerevisiae. J. Biotechnol. 2003, 100, 45-53. [CrossRef]

37. Rice, A.L.; Sacco, L.; Hyder, A.; Black, R.E. Malnutrition as an underlying cause of childhood deaths associated with infectious diseases in developing countries. Bull. World Health Organ. 2000, 78, 1207-1221.

38. Hertzler, S.R.; Clancy, S.M. Kefir improves lactose digestion and tolerance in adults with lactose maldigestion. J. Am. Diet. Assoc. 2003, 103, 582-587. [CrossRef] [PubMed]

39. Narvhusa, J.A.; Gadaga, T.H. The role of interaction between yeasts and lactic acid bacteria in African fermented milks: A review. Int. J. Food Microbiol. 2003, 86, 51-60. [CrossRef]

40. Farnworth, E.R.; Mainville, I. Kefir-A fermented milk product. In Handbook of Fermented Functional Foods, 2nd ed.; Farnworth, E.R., Ed.; CRC Press: Boca Raton, FL, USA, 2008; pp. 89-129, ISBN 978-1420053265.

41. Ozer, B.H.; Kirmaci, H.A. Functional milks and dairy beverages. Int. J. Dairy Technol. 2010, 63, 1-15. [CrossRef]

42. Bosch, A.; Golowczyc, M.A.; Abraham, A.G.; Garrote, G.L.; De Antoni, G.L.; Yantorno, O. Rapid discrimination of lactobacilli isolated from kefir grains by FT-IR spectroscopy. Int. J. Food Microbiol. 2006, 111, 280-287. [CrossRef]

43. Zajsek, K.; Gorsek, A. Modelling of batch kefir fermentation kinetics for ethanol production by mixed natural microflora. Food Bioprod. Process. 2010, 88, 55-60. [CrossRef]

44. Fazio, A.; La Torre, C.; Dalena, F.; Plastina, P. Screening of glucan and pectin contents in broad bean (Vicia faba L.) pods during maturation. Eur. Food Res. Technol. 2020, 246, 333-347. [CrossRef]

45. Fazio, A.; Caroleo, M.C.; Cione, E.; Plastina, P. Novel acrylic polymers for food packaging: Synthesis and antioxidant properties. Food Packag. Shelf Life 2017, 11, 84-90. [CrossRef]

Sample Availability: Samples of the compounds are available from the authors.

(C) 2020 by the authors. Licensee MDPI, Basel, Switzerland. This article is an open access article distributed under the terms and conditions of the Creative Commons Attribution (CC BY) license (http://creativecommons.org/licenses/by/4.0/). 